\title{
The effects of a plant proteinase inhibitor from Enterolobium contortisiliquum on human tumor cell lines
}

\author{
Adriana Miti Nakahata, ${ }^{1, a}$, Barbara Mayer,a, \\ Christian Ries ${ }^{3}$, Cláudia Alessandra Andrade de \\ Paula $^{1}$, Marisa Karow ${ }^{3}$, Peter Neth ${ }^{3}$, Misako U. \\ Sampaio ${ }^{1}$, Marianne Jochum ${ }^{3}$ and Maria Luiza \\ V. Oliva ${ }^{1, *}$
}

${ }^{1}$ Departamento de Bioquímica, Universidade Federal de São Paulo-Escola Paulista de Medicina, Rua Três de Maio 100, 04044-020, São Paulo, SP, Brazil

${ }^{2}$ Department of Surgery, Clinic Großhadern, Ludwig Maximilians University Munich, D-81377 Munich, Germany

${ }^{3}$ Division of Clinical Chemistry and Clinical Biochemistry, Ludwig Maximilians University Munich, D-80366 Munich, Germany

* Corresponding author

e-mail: olivaml.bioq@epm.br

\begin{abstract}
Supplementary to the efficient inhibition of trypsin, chymotrypsin, plasma kallikrein, and plasmin already described by the EcTI inhibitor from Enterolobium contortisiliquum, it also blocks human neutrophil elastase $\left(K_{\text {iapp }}=4.3 \mathrm{nM}\right)$ and prevents phorbol ester (PMA)-stimulated activation of matrix metalloproteinase (MMP)-2 probably via interference with membrane-type 1 (MT1)-MMP. Moreover, plasminogeninduced activation of proMMP-9 and processing of active MMP-2 was also inhibited. Furthermore, the effect of EcTI on the human cancer cell lines HCT116 and HT29 (colorectal), SkBr-3 and MCF-7 (breast), K562 and THP-1 (leukemia), as well as on human primary fibroblasts and human mesenchymal stem cells (hMSCs) was studied. EcTI inhibited in a concentration range of $1.0-2.5 \mu \mathrm{M}$ rather specifically tumor cell viability without targeting primary fibroblasts and hMSCs. Taken together, our data indicate that the polyspecific proteinase inhibitor EcTI prevents proMMP activation and is cytotoxic against tumor cells without affecting normal tissue remodeling fibroblasts or regenerative hMSCs being an important tool in the studies of tumor cell development and dissemination.
\end{abstract}

Keywords: cancer; Kunitz inhibitors; matrix metalloproteinases; mesenchymal stem cells; plant proteinases.

\footnotetext{
${ }^{a}$ These authors contributed equally to this work.
}

\section{Introduction}

Pathobiological events such as tumor progression include a complex network of proteinases and their inhibitors that affect different cellular signaling processes interfering directly or indirectly with cellular receptors (Hoekstra et al., 2001; Jedeszko and Sloane, 2004; Nagase et al., 2006; Lopez-Otin and Matrisian, 2007). The importance of proteinase activity for the enhancement of malignant tumor cell invasion and metastasis formation as a major cause of death in cancer patients has been studied extensively demonstrating that proteolysis-supported invasiveness, growth and movement of tumor cells are important characteristics contributing to malignancy (Woodhouse et al., 1997; Koblinski et al., 2000; Liotta and Clair, 2000; Nguyen, 2004; Duffy et al., 2008). Thereby, the extracellular matrix (ECM) plays a major role as a physical barrier that migrating cells have to surpass. The composition of the ECM, its three-dimensional organization and proteolytic remodeling are relevant determinants of microenvironmental signaling that controls cell shape, motility, growth, survival, and differentiation of stromal and tumor cells as well (Werb, 1997; Lukashev and Werb, 1998; Germanov et al., 2006; Wolf and Friedl, 2006; Bidard et al., 2008). As shown recently, ECM is substantially modified by proteinases produced by tumor or stromal cells resulting in the alteration of cell-cell and cell-matrix interactions which can, therefore, be prevented by application of effective proteinase inhibitors (DeClerck et al., 2004; Ohkoshi and Sasaki, 2005; Lah et al., 2006; Turk, 2006).

Among the numerous proteinases being responsible for ECM degradation, matrix metalloproteinases (MMPs) appear to be primarily involved in the initial step of this process. Based on their structure and substrate specificity, MMPs can be subdivided into main evolutionary groups: collagenases, gelatinases, stromelysins, membrane-type metallopeptidases (MT-MMP), and others (Nagase and Woessner, 1999; Nagase et al., 2006; Lazar et al., 2010).

Described as multifunctional enzymes capable of cleaving the ECM components (collagens, laminin, fibronectin, vitronectin, aggrecan, enactin, versican, perlecan, tenascin, elastin, and many others), these peptidases can affect cell proliferation, adhesion, migration, and invasion, as well as angiogenesis and metastasis, not only by degradation of the ECM, but also by the release of sequestered growth factors or the generation of bioactive fragments and degradation of functional proteins involved in cell-cell and cell-ECM interactions (Noel et al., 2008). Various studies correlate the high expression of MMP with the metastatic potential of tumors and poor survival in lung, prostate, stomach, colon, breast, ovary, pancreatic, oral squamous cell cancers, and other can- 
cers (Liu et al., 2007). In this regard, especially MMP-2 and MMP-9 (gelatinase A and gelatinase B, respectively) are known to degrade collagen type IV, the major component of basement membranes (Turpeenniemi-Hujanen, 2005; Fingleton, 2007). This assumption has been confirmed by many investigations correlating increased expression and activity of these gelatinases with poor prognosis and decreased survival of cancer patients (Stearns and Stearns, 1996; Kallakury et al., 2001; Bjorklund and Koivunen, 2005; Martin and Matrisian, 2007).

Because of their high degrading activity and potentially disastrous effect on the cell microenvironment, cellular MMPs are expressed in small amounts, and their cellular localization and activity are tightly controlled, either positively or negatively (Sternlicht and Werb, 2001; Zucker et al., 2003). For example, the pro-invasive, membrane-type 1 (MT1)-MMP (MMP-14), a major mediator of pericellular proteolytic events in cancer cells by cleaving ECM proteins, initiating activation of soluble MMPs and controls the functionality of cell adhesion (Egeblad and Werb, 2002; Seiki, 2003; Itoh and Seiki, 2006; Barbolina and Stack, 2008) is synthesized as a zymogen that requires proteolytic processing of the N-terminal inhibitory prodomain (Golubkov et al., 2010; Roghi et al., 2010). Once activated, MT1-MMP can be inhibited by its physiological inhibitors, tissue inhibitors of metalloproteinases-2, -3 , and -4 (TIMP-2, -3 , and -4) (Will et al., 1996; Brew and Nagase, 2010). MT1-MMP, as opposed to the soluble MMPs, is ideally positioned to regulate pericellular proteolysis and the functionality of cell receptors (Kessenbrock et al., 2010).

Through receptor-mediated signaling, MMPs can be activated by other peptidases that contribute to tumor formation, or influence the cellular microenvironment, tumor initiation and progression. For instance, the serine proteinase plasmin does not only degrade ECM components but is also an efficient activator of proMMP-3, which in turn activates proMMP-9 by sequential cleavage of the $\mathrm{Glu}^{40}-\mathrm{Met}^{41}$ and $\mathrm{Arg}^{87}-\mathrm{Phe}^{88}$ bonds (Murphy and Crabbe, 1995). In addition, plasmin contributes to direct activation of proMMP-9 as well as of proMMP-2 and proMMP-13 (Baramova et al., 1997). Similarly, human tumor-associated trypsin-2 is an efficient activator of proMMP-9 (Sorsa et al., 1997) and chymotrypsin-like proteinases have also been reported to activate proMMP-9 (Han et al., 2002) pointing to an extended interplay between serine proteinases and MMPs.

Furthermore, cysteine proteinases are also involved in this network, as demonstrated by functional imaging of tumor proteolysis (Sloane et al., 2006). These increased proteinase activities detected in tumor tissues confirm the importance of the proteolytic network for the development of cancer and indicate that tumor cell invasion and metastasis are facilitated by uncontrolled interactions between proteolytic enzymes (Moll et al., 1990; Leipner and Saller, 2000; Skrzydlewska et al., 2005; Sloane et al., 2006). Hence, inhibition of extracellular released proteinases could be an attractive approach for cancer therapy (Lah et al., 2006; Turk, 2006). Considering the complex proteinase network, an inhibitor able to interfere with more than one target enzyme could be useful

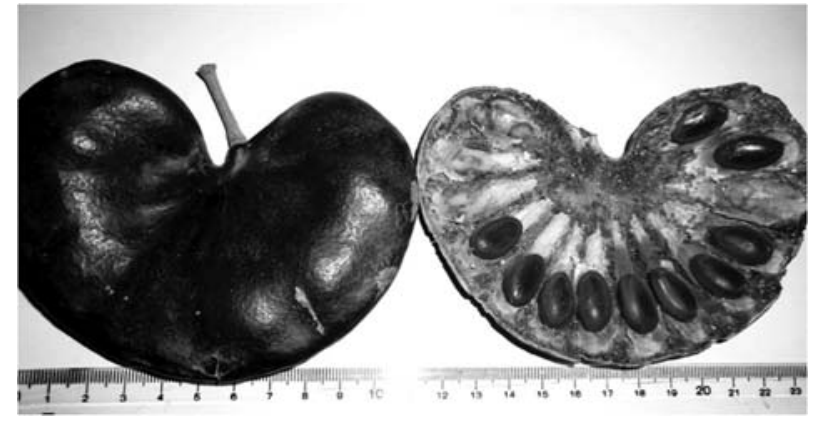

Figure 1 Enterolobium contortisiliquum fruit with the seeds. The bar corresponds to $23 \mathrm{~cm}$.

for studies of tumor progression. In this direction, the action of the Enterolobium contortisiliquum trypsin inhibitor (EcTI), a potent polyspecific Kunitz-type inhibitor (Batista et al., 1996) was evaluated compared with the chemotherapeutic drug 5-fluorouracil (5-FU) (Diasio and Johnson, 2000) on cell viability of colorectal, breast, leukemic tumor cell lines compared with the effect on fibroblast and mesenchymal stem cells.

\section{Results}

\section{Proteinase inhibition}

Using a modified biochemical approach for protein purification, we achieved enough material for further characterization of the Kunitz-type inhibitor EcTI from seeds of the Brazilian plant E. contortisiliquum (Figure 1). The inhibitor homogeneity was assessed by a reverse phase chromatography with acetonitrile gradient (Figure 2) and by SDS-PAGE (Figure 2, insert), in which it appears, in a reducing condition, as a double polypeptide chains protein with molecular masses of $16 \mathrm{kDa}$ and $4.0 \mathrm{kDa}$, respectively. EcTI purity was also confirmed by $\mathrm{N}$-terminal sequence determination and by mass spectrometry. The $20 \mathrm{kDa}$ inhibitor was shown to block the activity of trypsin, chymotrypsin, plasma kallikrein, and plasmin (Table 1) as previously described (Batista et al., 1996). Here, we analyzed the effect of EcTI on human neutrophil elastase (HNE) that was inhibited with a $K_{\text {iapp }}$ of 55 nм (Table 1).

Owing to the effect of EcTI on plasmin activity, we investigated if the cell-associated proMMP activation was influenced by EcTI in comparison to BbCI (an inhibitor of elastase and cysteine proteinases) and BbKl (a kallikrein inhibitor), as well as to the general serine proteinase inhibitor aprotinin. Similar to EcTI, both BbCI and BbKI were isolated from plant seeds (de Oliveira et al., 2001; Oliva et al., 2001), whereas aprotinin is derived from animal tissue (Fritz and Wunderer, 1983). HT1080 fibrosarcoma cells were used as a cell model, because these cells are known to express proMMP-9, proMMP-2, and MT1-MMP which is required for proMMP-2 activation on the cell surface (Moll et al., 1990; Stanton et al., 1998). Zymographic analysis of HT1080 culture supernatants demonstrated constitutive 


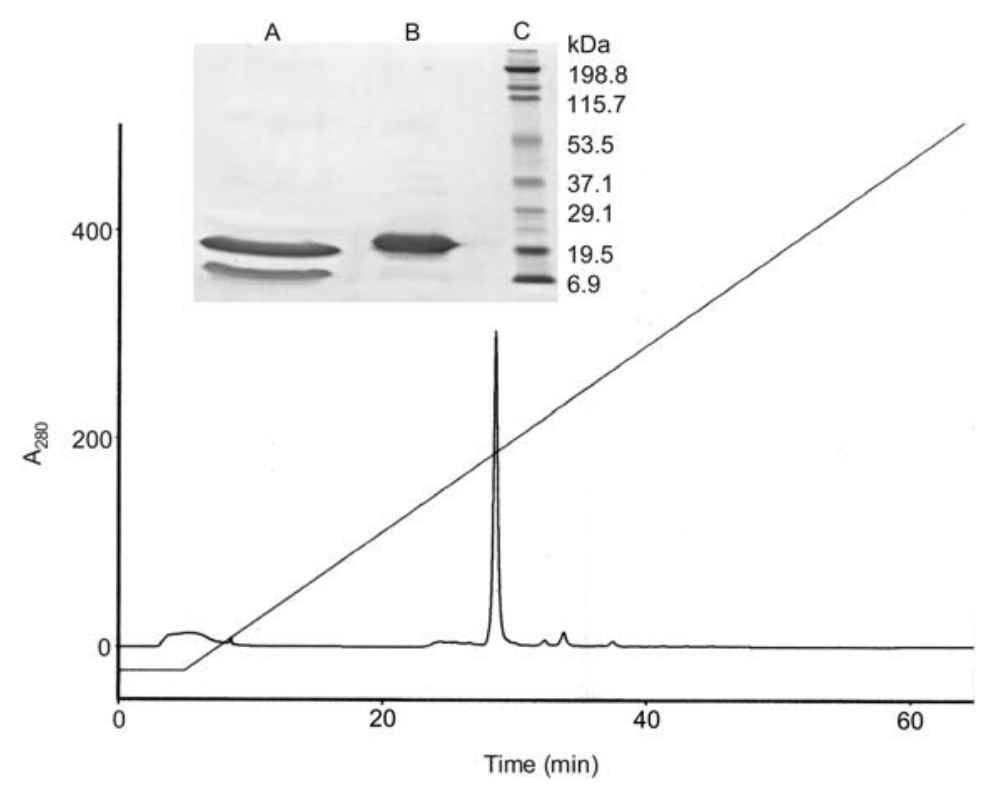

Figure 2 Reversed-phase (RP) chromatography.

RP chromatography was performed on a C18 column equilibrated with $0.1 \%$ TFA and developed with an acetonitrile gradient (0-100\%) in TFA; the flow rate was $0.5 \mathrm{ml} / \mathrm{min}$. Sample: EcTI $(400 \mu \mathrm{g})$ after size exclusion chromatography on Superdex 75 . Inset: SDS-PAGE analysis of purified forms of EcTI. Reducing condition, as a two-polypeptide chain protein with molecular masses of $16 \mathrm{kDa}$ and $4.0 \mathrm{kDa}$, respectively (lane A); EcTI: $20 \mathrm{kDa}$ (lane B); molecular mass standards (lane C).

secretion of proMMP-9 $(\sim 94 \mathrm{kDa})$ and proMMP-2 $(\sim 72 \mathrm{kDa})$ together with low amounts of active MMP-2 ( $\sim 66 \mathrm{kDa})$. Addition of PMA to the cells enhanced the release of proMMP-9 from the cells and increased the formation of active 66-kDa MMP-2 (Figure 3). These findings are in agreement with previous results obtained from HT1080 cells (Moll et al., 1990; Baramova et al., 1997). Remarkably, the co-incubation of HT1080 with EcTI completely blocked PMA-stimulated proMMP-2 activation in contrast to BbCI, BbKI, and aprotinin which had no similar effect (Figure 3), indicating an interference of EcTI with MT1-MMP-mediated activation of proMMP-2. As determined by the trypan blue exclusion test, cell viability was not affected at inhibitor concentrations of $1 \mu \mathrm{M}$ used in the experiments.

Furthermore, we analyzed whether HT1080 incubation with plasminogen as a source for uPA/PAR-dependent cellassociated formation of plasmin would influence proMMP activation. Plasmin is known for its ability to convert the 66$\mathrm{kDa}$ intermediate active form of proMMP-2 into mature 64kDa MMP-2 (Baramova et al., 1997). In addition, plasmin can activate proMMP-9 (Ramos-DeSimone et al., 1999). Plasminogen alone or in combination with PMA led to the disappearance of 66-kDa MMP-2 and emergence of 64-kDa MMP-2 in HT1080 culture supernatants as shown by zymography (Figure 3). Addition of EcTI abolished the generation of 66-kDa and 64-kDa MMP-2 in plasminogen/PMA-treated cells, whereas BbCI and BbKI had no effect. Although aprotinin also did not prevent proMMP-2 activation to the intermediate active 66-kDa form, it successfully inhibited a further presumably plasmin-mediated conversion to the 64kDa active MMP-2. Moreover, exposition of HT1080 cells to plasminogen enabled activation of proMMP-9 into 82-kDa MMP-9 both in the absence and presence of PMA. This process was slightly decreased by EcTI, but was unaffected by $\mathrm{BbCI}$ or BbKI. Because aprotinin, a potent plasmin inhibitor, efficiently blocked proMMP-9 activation under these conditions, the EcTI effect in this process is probably as a result of inhibition of plasmin.

\section{Reduction of cell viability}

The effect of EcTI on the viability of human tumor cell lines and primary cells with regenerative capacity such as human fibroblasts was analyzed by the MTS assay which allows the detection of metabolically intact cells. In addition, the effect of EcTI was compared with that of 5-FU as a well-known clinically applied cell-toxic agent. As demonstrated in Figure 4 , the antimetabolic influence of 5-FU on most tumor cell lines did not vary significantly by increasing its concentration from $1 \mu \mathrm{M}$ to $12.5 \mu \mathrm{M}$. 5-FU shows reduction of tumor cell viability between $11 \%$ and $56 \%$ depending on the tested cell lines after $24 \mathrm{~h}$ incubation time. The toxic influence of the chemotherapeutic agent increased up to $79 \%$ on K562 and THP1 lines at $48 \mathrm{~h}$ incubation. By contrast, EcTI exhibits a significant concentration-dependent cell-toxic effect on tumor cell lines. The reduction of cell viability varied approximately between $13 \%$ and $84 \%$ already after $24 \mathrm{~h}$ incubation time and increased slightly up to $85 \%$ at $48 \mathrm{~h}$ (Figure 4).

Although EcTI shows reduction of tumor cell viability, primary fibroblast metabolism was not impaired, at least at concentrations below $50 \mu \mathrm{M}$ (Figure 5). Indeed, on primary 
Table 1 Inhibitory properties of EcTI.

\begin{tabular}{ll}
\hline Mammalian serine proteinase & $K_{\text {iapp }}$ \\
\hline Bovine trypsin & 0.88 \\
Bovine chymotrypsin & 1.11 \\
Bovine pancreatic elastase & n.i. \\
Human neutrophil elastase & 55 \\
Human plasma kallikrein & 6.1 \\
Human factor Xa & n.i. \\
Human plasmin & 9.36 \\
Porcine pancreatic kallikrein & n.i. \\
\hline
\end{tabular}

'n.i.': no detectable inhibition. Inhibitor and proteinase were incubated at $37^{\circ} \mathrm{C}$ with one of the following proteinases and respective substrates: trypsin $(7.0 \mathrm{~nm}$ in $0.05 \mathrm{M}$ Tris- $\mathrm{HCl}, \mathrm{pH}$ $8.0,0.02 \% \mathrm{CaCl}_{2} ; 1.0 \mathrm{~mm}$ BAPA), chymotrypsin (76 nM in $0.1 \mathrm{M}$ Tris- $\mathrm{HCl}, \mathrm{pH} 8.0,0.02 \% \mathrm{CaCl}_{2} ; 2.0 \mathrm{~mm}$ Suc-PhepNan), HuPK, human plasma kallikrein (67 nM in $0.05 \mathrm{M}$ Tris-HCl, pH 8.0; 0.5 mm H-D-Pro-Phe-Arg-pNan); PoPK, porcine pancreatic kallikrein $(2.6 \mathrm{~nm}$ in $0.1 \mathrm{~m}$ Tris- $\mathrm{HCl}, \mathrm{pH}$ 8.0; $0.8 \mathrm{~mm}$ Ac-Phe-Arg-pNan), PPE, porcine pancreatic elastase $(71 \mathrm{nM}$ in $0.05 \mathrm{M}$ Tris- $\mathrm{HCl}, \mathrm{pH} 8.0,0.5 \mathrm{M} \mathrm{NaCl}$; $0.5 \mathrm{~mm}$ MeO-Suc-Ala-Ala-Pro-Val-pNan), HNE, human neutrophil elastase ( $25 \mathrm{~nm}$ in $0.05 \mathrm{~m}$ Tris-HCl, pH 7.0, $0.5 \mathrm{M}$ $\mathrm{NaCl}$; $0.5 \mathrm{~mm} \mathrm{MeO}-$ Suc-Ala-Ala-Pro-Val-pNan), factor Xa (56 nM in Tris- $\mathrm{HCl} 0.05 \mathrm{M}, \mathrm{pH} 8.0 ; 1.5 \mathrm{~mm}$ Boc-Ile-GluGly-Arg-AMC), and plasmin (3.5 nM in $0.1 \mathrm{M}$ Tris- $\mathrm{HCl}$, $0.2 \mathrm{M} \mathrm{NaCl}, \mathrm{pH} 7.4 ; 1.0 \mathrm{~mm}$ H-D-Val-Leu-Lys-pNan). $K_{\text {iapp }}$ values were determined by adjusting the experimental points to the equation for tight binding, using nonlinear regression with the Grafit program (Morrison, 1982).

human mesenchymal stem cells (hMSCs), EcTI in a concentration of $10 \mu \mathrm{M}$ or $100 \mu \mathrm{M}$, even after 7 days incubation did not affect cell proliferation as measured by binding of a fluorescent dye to cellular nucleic acids differing from 5-FU, whereas $10 \mu \mathrm{M}$ 5-FU blocked hMSC proliferation up to $80 \%$ (Figure 6).

\section{Discussion}

A disturbed interaction of proteinases and their inhibitors seems to be the main reason for enhanced tumor cell migration and invasion of healthy tissue, leading to metastasis formation and eventually organ destruction. This assumption is based on the fact that the failure of endogenous inhibitors to counterbalance overwhelming destructive proteinase activities has been shown to correlate with the progression of various tumor entities such as breast, colon cancer, or leukemia (Skrzydlewska et al., 2005; Sloane et al., 2006; Bhoola et al., 2007). Therefore, the search for effective inhibitors applicable in such clinical situations was and still is a challenging topic of tumor therapy-relevant research (Lah et al., 2006; Turk, 2006).

In recent years, many proteinase inhibitors have been found in plants, especially in legume seeds (Nakahata et al., 2006; Oliva and Sampaio, 2008; Roy and Dutta, 2009; Macedo et al., 2010; Prasad et al., 2010). One major aspect of interest in plant-derived inhibitors is to discover the relationship of structure and specificity or selectivity of these inhibitors for different proteinases enabling structural modifications to target a variety of proteinases, which are significantly involved in tumor development. Thereby, not only growth and migration of tumor cells (Woodhouse et al., 1997; Koblinski et al., 2000; Park et al., 2000) but also their adhesion capacity and cell metabolism (Miyasaka, 1995; Braga, 2000; Fashena and Thomas, 2000; Parise et al., 2000; Gocheva and Joyce, 2007) should be affected to eliminate malignant diseases.

The trypsin inhibitor, EcTI, purified from the seeds of the Leguminosae E. contortisiliquum was previously characterized as a polyspecific $20 \mathrm{kDa}$ serine proteinase inhibitor that inhibits the digestion enzymes trypsin and chymotrypsin, in addition to plasma kallikrein and plasmin which are involved in the intrinsic pathway of blood clotting and fibrinolysis,

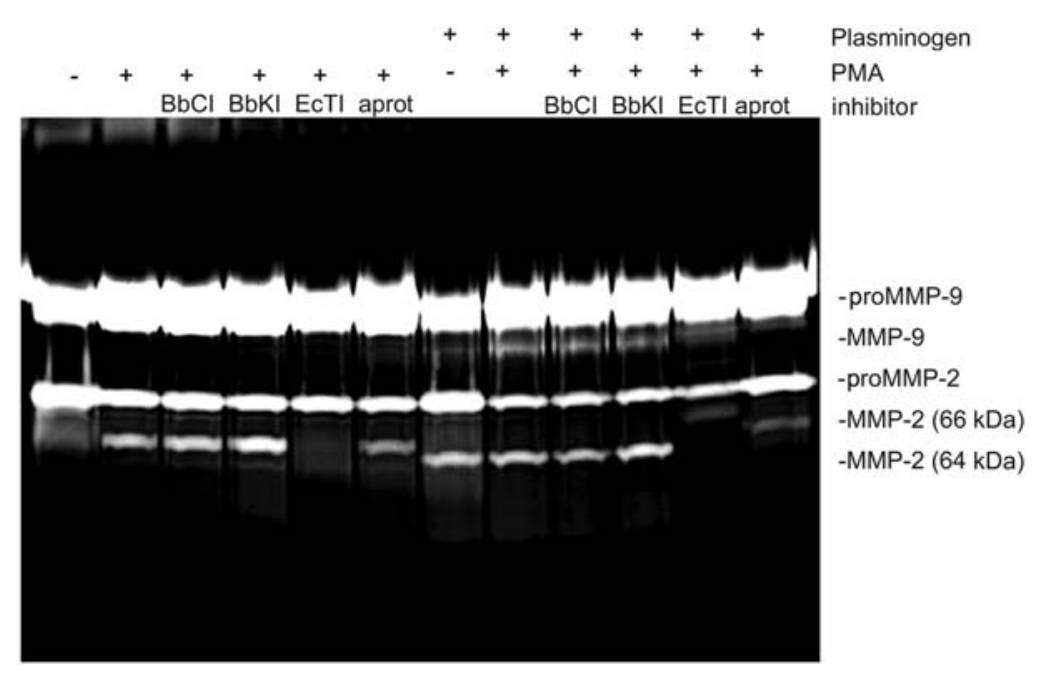

Figure 3 Effect of EcTI on the activation of proMMP-9 and proMMP-2 induced by plasminogen and/or PMA.

HT1080 cells were incubated in the absence and presence of PMA $(25 \mathrm{ng} / \mathrm{ml})$, plasminogen $(10 \mu \mathrm{g} / \mathrm{ml})$ and the serine proteinase inhibitors BbCI (BC), BbKI (BK), EcTI (ET), or aprotinin (1 $\mu \mathrm{M}$ each). After $48 \mathrm{~h}$ culture, supernatants were collected and analyzed for the presence of (pro)MMP-9 and (pro)MMP-2 forms using gelatin zymography. 

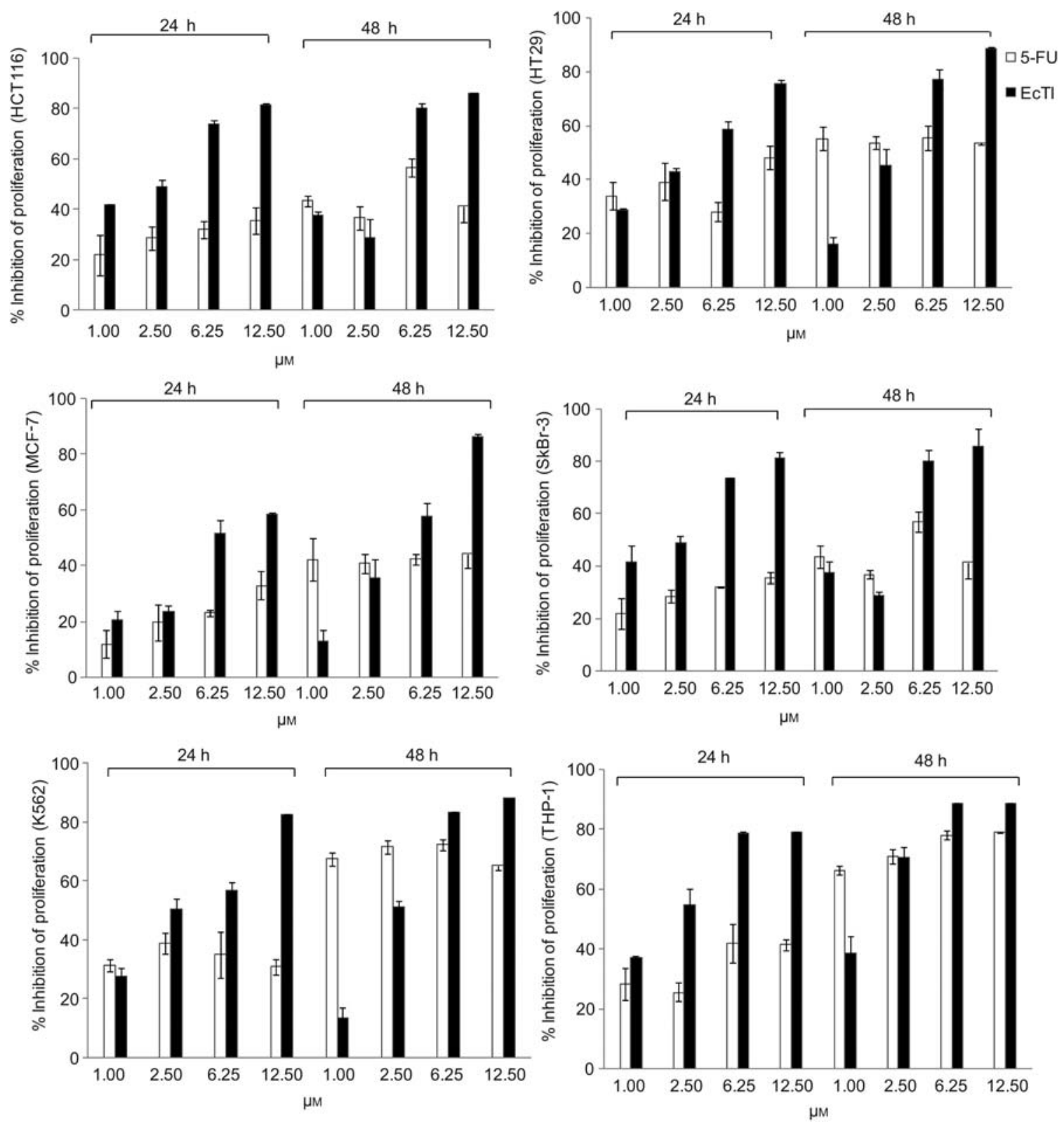

Figure 4 Effects of 5-FU or EcTI or 5-FU+EcTI on the human cancer cell lines HCT116 and HT29 (colorectal), SkBr-3 and MCF-7 (breast), K562 and THP-1 (leukemia).

The cells were incubated for $24 \mathrm{~h}$ and thereafter treated with increasing drug concentrations for a further $24 \mathrm{~h}$ and $48 \mathrm{~h}$. Cell viability was measured with the MTS assay evaluating the bioreduction of MTS into a water soluble formazan; EcTI $* p<0.05$ vs. 5 -FU plus EcTI.

respectively (Batista et al., 1996; Oliva and Sampaio, 2009). In the present study, we focused on the action of EcTI on neutrophil and pancreatic elastase as well as on the activation of MMPs. Furthermore, the influence of EcTI on the metabolism or proliferation of human tumor cell lines, fibroblasts, and hMSCs was studied.

As demonstrated here, EcTI does not target porcine pancreatic elastase but efficiently inhibits purified HNE. Because HNE is well-known to disintegrate ECM proteins and to inactivate endogenous serine proteinase inhibitors such as $\alpha_{2}$-antiplasmin and PAI-1, the main inhibitors of the fibrinolytic system, the enzyme might readily contribute to uncontrolled proteinase activities and thus to tumor cell invasion and metastasis in vivo (Hildenbrand et al., 2008). HNE can promote the adhesion of neutrophils and tumor cells to vascular endothelial cells thereby further facilitating tumor metastasis (Nozawa et al., 2000). Interestingly, HNE is produced not only by neutrophils but also by diverse cancer cell lines, in particular by breast cancer cells (Sun and Yang, 2004; Sato et al., 2006). Although the main origin of HNE in tumor tissue extracts is, therefore, not yet clear, extended measurement of HNE in human breast cancer tissue samples revealed a distinct correlation between elevated elastase levels, breast cancer metastasis, and poor prognosis of the 


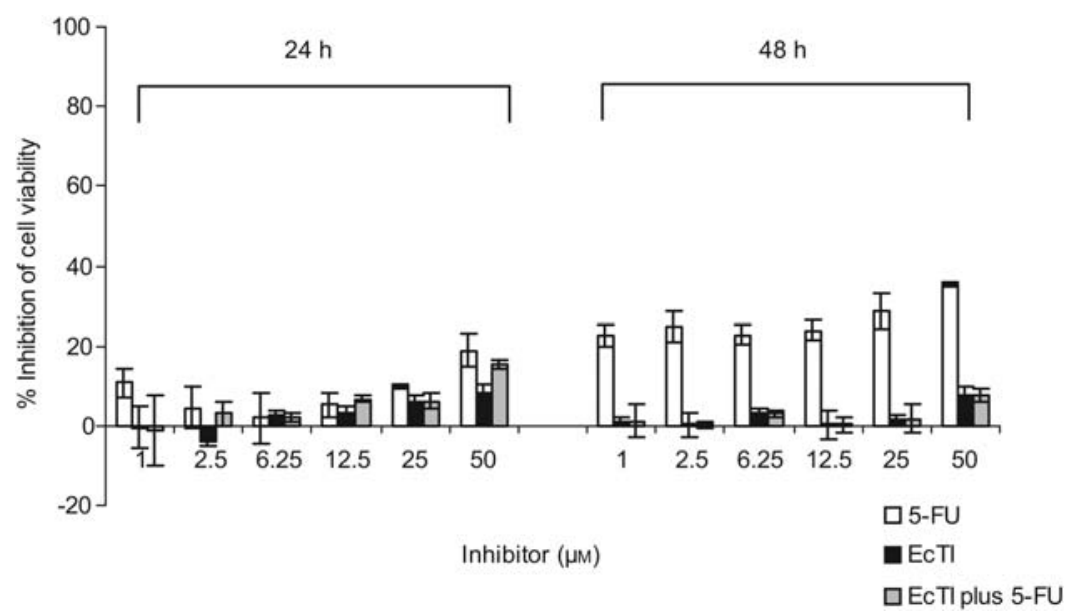

Figure 5 Effects of EcTI on cell viability of primary fibroblasts.

The cells were incubated for $24 \mathrm{~h}$ and then treated with increasing concentration of EcTI for a further $24 \mathrm{~h}$ and $48 \mathrm{~h}$. Cell viability was measured with the MTS assay evaluating the bioreduction of MTS into a water soluble formazan; EcTI $* p<0.05$ vs. 5-FU plus EcTI.

patients (Foekens et al., 2003a). Furthermore, increased elastase levels were associated with the failure of tamoxifen treatment in advanced breast cancer stages, indicating a presumable interference of HNE with growth factors or their receptors (Foekens et al., 2003b). Hence, an effective inhibition of elastase by EcTI as shown here in vitro might be important for the studies on the involvement of this proteinase on recurrence and progression of tumor.

Taking the interaction of HNE with the uPA/PAR/PAI-1 system into account which significantly contributes to the generation of the potent ECM-degrading plasmin as a further important mediator of tumor cell invasion and metastasis (Janicke et al., 2001; Duffy and Duggan, 2004), the simultaneous inhibition of HNE and plasmin by EcTI can render the tumor cell antiproliferative effect of this plant-derived inhibitor. As the gelatinases MMP-2 and MMP-9 are mainly expressed and secreted as zymogens requiring activation by serine or cysteine proteinases or already active MMPs (Shamamian et al., 2001), we were interested to evaluate whether EcTI is able to interfere directly or indirectly with the activation of these gelatinases in comparison to aprotinin and additional plant-derived serine proteinase inhibitors. HT1080 fibrosarcoma cells which released 94-kDa proMMP-9, 72$\mathrm{kDa}$ proMMP2, and small amounts of active 66-kDa MMP2 as previously shown by others (Moll et al., 1990) were used for this studies. Addition of PMA stimulated the formation of 66-kDa MMP-2 confirming former data of Stanton and colleagues who demonstrated MT1-MMP to be responsible for this step (Stanton et al., 1998). Our finding that EcTI completely blocked this PMA-evoked proMMP-2 activation suggests a possible direct interaction of EcTI with MT1-MMP activity and/or expression. This influence seems to be independent of serine proteinases, because aprotinin as a general serine proteinase inhibitor did not show a similar effect. When plasminogen was added to HT1080 cells, 66kDa MMP-2 was entirely transformed into 64-kDa MMP-2. Our data are in agreement with previous results of others, suggesting a two-step model of proMMP-2 activation. In a first step, MT1-MMP on the cell surface mediates activation proMMP-2 into 66-kDa MMP-2 which is then released from the cells (Nagase et al., 2006). In a second step, plasmin derived from the cell-associated activation of plasminogen by the UPA/PAR system can further process intermediate 66kDa MMP-2 into fully active 64-kDa MMP-2 (Baramova et al., 1997). Interestingly, we found that EcTI efficiently inhibited the formation of both 66-kDa and 64-kDa MMP-2 under PMA/plasminogen-stimulating conditions, whereas aprotinin could only block transformation into 64-kDa MMP-2 but, similar to aprotinin EcTI, decreases the plasminogen-induced proMMP-9 activation approving direct inhibition of plasmin by the plant inhibitor. By contrast, neither the plant-derived elastase/cysteine proteinase inhibitor BbCI nor the kallikrein inhibitor BbKI (Oliva et al., 2001; Araujo et al., 2005)

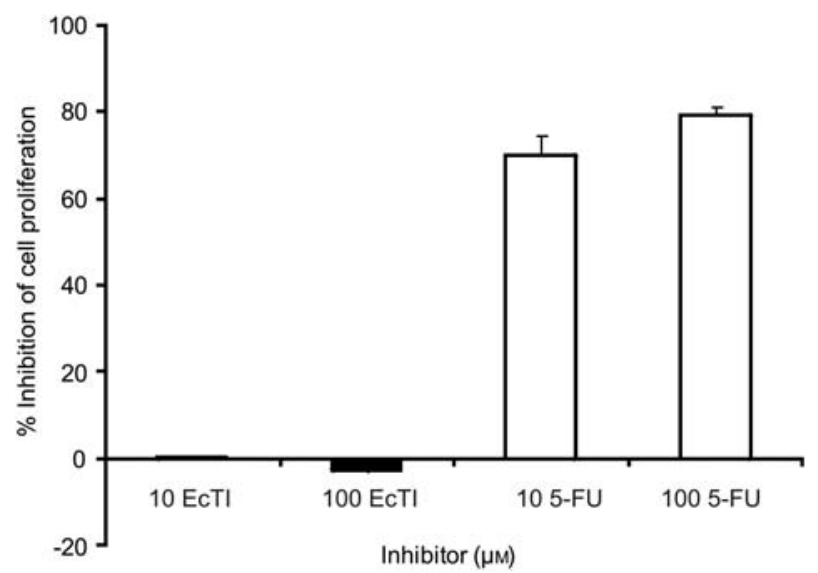

Figure 6 Effects of EcTI or 5-FU on cell proliferation of hMSCs. hMSCs were preincubated for $24 \mathrm{~h}$ and then treated with $10 \mu \mathrm{M}$ and $100 \mu \mathrm{M} 5$-FU or EcTI for further 7 days. Cell proliferation was measured by binding of a fluorescent dye to cellular nucleic acids using the CyQuant assay. 
showed any effect on the proMMP-2 and -9 activation, indicating that the respective target serine proteinases do not interact with the MMP system in our cell model.

It is of special interest that whereas 5-FU massively cuts down the proliferation rates of hMSCs already at low concentrations, EcTI, even at high doses, did not affect hMSC proliferation, which indicates that it is a good candidate for a selective tumor therapy approach without affecting the regenerative capacity of the hMSC compartment. In conclusion, our findings provide first evidence that EcTI is capable of blocking the activation of proMMP-2 and -9 suggesting its potential usefulness in therapeutic applications aimed to target MMP-mediated tumor growth and invasion.

\section{Materials and methods}

\section{Inhibitor purification}

The inhibitor was purified with some modifications according to a method described previously (Batista et al., 1996). Briefly, Enterolobium contortisiliquum seeds (Figure 1) were swollen in $0.15 \mathrm{M}$ $\mathrm{NaCl}$ 1:40 (w/v) and homogenized in a blender. The proteins in the crude extract after centrifugation at $4000 \mathrm{~g}$ were precipitated by acetone $(80 \% \mathrm{v} / \mathrm{v})$ at $4^{\circ} \mathrm{C}$. Thereafter, the sediment was separated by centrifugation, dried under vacuum, and dissolved in $0.05 \mathrm{M}$ Tris$\mathrm{HCl}$ buffer, $\mathrm{pH}$ 8.0. The soluble fraction was applied onto a DEAESephadex column $(2 \times 25 \mathrm{~cm})$ equilibrated with $0.1 \mathrm{M}$ Tris- $\mathrm{HCl}$ buffer, $\mathrm{pH}$ 8.0. After extensive washing with the equilibrium buffer, the inhibitor was eluted with $0.15 \mathrm{M} \mathrm{NaCl}$ in the same buffer and the protein was verified by absorbance measurement at $280 \mathrm{~nm}$. Furthermore, the trypsin inhibitory activity was determined using $1 \mathrm{~mm} \alpha$-benzoyl-D-L-arginine- $p$-nitroanilide (BAPA) as substrate (Batista et al., 1996). The fractions containing trypsin inhibitory activity were pooled and applied in a trypsin-Sepharose resin and subsequently on gel filtration chromatography in a Superdex 75 column equilibrated with $0.05 \mathrm{M}$ Tris- $\mathrm{HCl}$ buffer, $\mathrm{pH}$ 8.0, using an ÄKTA Purifier (GE Healthcare, Uppsala, Sweden).

\section{Proteinase inhibition assays}

The effect of EcTI on the proteolytic activity of HNE (Sigma Chemical Company, St. Louis, MO) was assayed with the specific peptide substrates MeO-Suc-Ala-Ala-Pro-Val-pNan (Calbiochem, San Diego, CA, USA). The assays were performed in a 96-well plate in a final volume of $250 \mu \mathrm{l}$ per well at $37^{\circ} \mathrm{C}$ using $28 \mathrm{~nm} \mathrm{HNE}$ (in $0.05 \mathrm{M}$ Tris- $\mathrm{HCl}$, containing $0.5 \mathrm{M} \mathrm{NaCl}$ at $\mathrm{pH} 7.0$ and with $11.0 \mathrm{~mm}$ MeO-Suc-Ala-Ala-Ala-pNan). The inhibitor EcTI was applied in concentrations ranging from $20 \mathrm{~nm}$ to $100 \mathrm{~nm}$ and $K_{\text {iapp }}$ was determined as described (Araujo et al., 2005; Sumikawa et al., 2006).

\section{Studies on proMMP activation}

The influence of EcTI in comparison to other serine proteinase inhibitors such as Bauhinia bauhinioides kallikrein inhibitor (BbKI) (Oliva et al., 2001) and cysteine inhibitor (BbCI) (de Oliveira et al., 2001) or aprotinin (Dani et al., 1963) on secretion and activation of proMMPs was analyzed using the HT1080 fibrosarcoma cell model (Moll et al., 1990). Briefly, HT1080 cells were incubated at $37^{\circ} \mathrm{C}$ under serum-free conditions in the absence and presence of $25 \mathrm{ng} /$ $\mathrm{ml}$ phorbol 12-myristate 13-acetate (PMA) which stimulates proMMP expression. Furthermore, plasminogen $(10 \mu \mathrm{g} / \mathrm{ml})$ was applied as a proMMP activator after being converted to plasmin by the cell-associated uPA/PAR system. In addition, cells were simultaneously incubated with and without EcTI, BbCI, BbKI, or aprotinin $(1 \mu \mathrm{M}$ each). After $48 \mathrm{~h}$ culture, supernatants were collected and analyzed for the presence of (pro)MMP-2 and (pro)MMP-9 by gelatin zymography. Two independent experiments were performed. Cell viability was determined by the ability of the cells to exclude trypan blue.

\section{Cell cultivation}

The following human cancer cell lines were purchased from ACCT (ATCC, Minnesota, USA) and cultured in RPMI 1640 (Gibco BRL/ Life Technology, Carlsbad, CA, USA) supplemented with $10 \%$ fetal bovine serum (Sigma Chemical Company), $100 \mu \mathrm{g} / \mathrm{ml}$ streptomycin, and $100 \mathrm{IU} / \mathrm{ml}$ penicillin at $37^{\circ} \mathrm{C}$ in an atmosphere of $5 \% \mathrm{CO}_{2}$ : HCT116 and HT-29 (colorectal cancer), SkBr-3 and MCF-7 (breast cancer), HT 1080 (fibrosarcoma), as well as K562 (chronic myeloid leukemia in blast crisis) and THP-1 (acute monocytic leukemia).

Human primary culture of fibroblasts isolated from amniotic fluid was kindly donated by Prof. Walter Pinto Jr. (Campinas, Brazil) and used between passages 3 and 6 . The cells were maintained in DMEM medium (Gibco BRL/Life Technology) supplemented with $10 \%$ fetal bovine serum (Sigma Chemical Company), 2 mM L-glutamine, $100 \mu \mathrm{g} / \mathrm{ml}$ streptomycin, and $100 \mathrm{IU} / \mathrm{ml}$ penicillin at $37^{\circ} \mathrm{C}$ in an atmosphere of $5 \% \mathrm{CO}_{2}$.

Cryopreserved hMSCs were purchased from Cambrex (Walkersville, MD, USA). The cultivation of hMSCs was performed in $\alpha$ MEM medium supplemented with $16.5 \%$ fetal bovine serum and $100 \mathrm{IU} / \mathrm{ml}$ penicillin/streptomycin. Cells were grown at $37^{\circ} \mathrm{C}$ in a humidified atmosphere containing $95 \%$ air and $5 \% \mathrm{CO}_{2}$ according to the supplier's instructions. Medium was refreshed twice a week and cells were used for further cultivation or cryopreservation prior to reaching confluence. hMSCs were used at the 5th or 6th passage of cultivation and stem cell features were assessed by differentiation into various mesodermal lineages as previously described (Hoelters et al., 2005).

\section{MTS cell viability assay}

To evaluate cell viability, tumor cells and fibroblasts, respectively, were preincubated $24 \mathrm{~h}$ (for fast-growing cell lines $4 \times 10^{3}$ cells/ $100 \mu \mathrm{l} /$ well) or $48 \mathrm{~h}$ (for slow-growing cell lines $8 \times 10^{3}$ cells $/ 100$ $\mu \mathrm{l} /$ well) in 96-well plates (Costar, Corning Incorporated, New York, USA) at $37^{\circ} \mathrm{C}$ in an atmosphere of $5.0 \% \mathrm{CO}_{2}$. After these times, EcTI and the chemotherapeutic drug 5-FU were added in a concentration range of 1.0-12.5 $\mu \mathrm{M}$ and incubated for a further $24 \mathrm{~h}$ and $48 \mathrm{~h}$. Thereafter, cell viability was determined with MTS (Promega, Madison, WI, USA) and phenazine methosulfate (PMS; Sigma) according to the method described previously (Chao and Chu, 2004). The tetrazolium salt MTS undergoes a color change caused by its bioreduction into a water-soluble formazan. This conversion is accomplished by dehydrogenases present in active mitochondria and occurs as such only in living cells. The quantity of formazan measured by light absorbance is directly proportional to the number of living cells. In detail, MTS ( $2 \mathrm{mg} / \mathrm{ml} ; \mathrm{pH} 6.5)$ and PMS (3 mM) were dissolved in PBS, filter-sterilized, and stored at $-20^{\circ} \mathrm{C}$ in lightprotected containers. To enhance the cellular reduction of MTS, PMS was combined with MTS in a 20:1 ratio immediately before use. Each cell-containing well of the 96-well plate was supplemented with $20 \mu \mathrm{l}$ of MTS/PMS solution and incubated at $37^{\circ} \mathrm{C}$ in a humidified $5 \% \mathrm{CO}_{2}$ atmosphere for $3 \mathrm{~h}$. The absorbance was read at $490 \mathrm{~nm}$ using a spectrophotometer (SpectraCount model from Packard, Perkin Elmer, California, USA). Every cell set was ana- 
lyzed in triplicate. Data were recorded manually and calculated with the Microsoft Excel program.

\section{CyQuant cell proliferation assay}

To study the influence of EcTI and 5-FU on hMSC proliferation, 64000 cells were seeded into each cavity of a 6-well plate (Nunc, Roskilde, Denmark) containing $2 \mathrm{ml} \alpha \mathrm{MEM}$ medium supplemented with $16.5 \%$ fetal bovine serum and $100 \mathrm{IU} / \mathrm{ml}$ penicillin/streptomycin solution. Then, $24 \mathrm{~h}$ later medium was refreshed and two different concentrations $(10 \mu \mathrm{M}$ and $100 \mu \mathrm{M})$ of EcTI or 5-FU were added. After 7 days of incubation, the proliferation capacity of hMSCs was assayed via binding of a fluorescent dye to cellular nucleic acids using the CyQuant cell proliferation assay kit (Molecular Probes, Eugene, OR, USA) according to the manufacturer's protocol. Briefly, for fixation cells were washed in PBS and stored at $-80^{\circ} \mathrm{C}$ until further processing. After thawing, cell lysis was performed in $250 \mu 1$ lysis buffer. Two $100 \mu 1$ aliquots of each cell set were transferred into the cavities of a 96-well microtiter plate (Corning Costar, New York, NY, USA) and mixed with $100 \mu \mathrm{l}$ of cell lysis buffer containing CyQuant GR dye. After 5 min of incubation, fluorescence was measured using a fluorescence microtiter plate reader (HTS 7000 Bio Assay Reader; Perkin Elmer, California, USA) at $480 \mathrm{~nm}$ excitation and $530 \mathrm{~nm}$ emission. For each experiment, a standard calibration curve was generated by plotting the measured fluorescence values of the samples versus the respective cell number that had been determined before using a hematocytometer.

\section{Statistics}

Experiments were performed at least three times and data are shown as mean \pm SD. Student's $t$-test was used to determine significance.

\section{Acknowledgments}

We are grateful to Lucimeire A. de Santana and Magda T. de Sousa for technical assistance and to Coordenação de Aperfeiçoamento de Pessoal de Nível Superior/Deutscher Akademischer Austausch Dienst (CAPES/DAAD), Fundação de Amparo á Pesquisa do Estado de São Paulo (FAPESP), and Ministério da Ciência e Tecnologia/ Conselho Nacional de Desenvolvimento Político e Tecnológico (MCT/CNPq) for providing financial support.

\section{Conflict of interest statement}

The authors declare that no conflict of interest exists.

\section{References}

Araujo, A.P., Hansen, D., Vieira, D.F., Oliveira, C., Santana, L.A., Beltramini, L.M., Sampaio, C.A., Sampaio, M.U., and Oliva, M.L. (2005). Kunitz-type Bauhinia bauhinioides inhibitors devoid of disulfide bridges: isolation of the cDNAs, heterologous expression and structural studies. Biol. Chem. 386, 561-568.

Baramova, E.N., Bajou, K., Remacle, A., L'Hoir, C., Krell, H.W., Weidle, U.H., Noel, A., and Foidart, J.M. (1997). Involvement of PA/plasmin system in the processing of pro-MMP-9 and in the second step of pro-MMP-2 activation. FEBS Lett. 405, $157-162$.
Barbolina, M.V. and Stack, M.S. (2008). Membrane type 1-matrix metalloproteinase: substrate diversity in pericellular proteolysis. Semin. Cell Dev. Biol. 19, 24-33.

Batista, I.F., Oliva, M.L., Araujo, M.S., Sampaio, M.U., Richardson, M., Fritz, H., and Sampaio, C.A. (1996). Primary structure of a Kunitz-type trypsin inhibitor from Enterolobium contortisiliquum seeds. Phytochemistry 4, 1017-1022.

Bhoola, K.D., Misso, N.L., Naran, A., and Thompson, P.J. (2007). Current status of tissue kallikrein inhibitors: importance in cancer. Curr. Opin. Investig. Drugs 8, 462-468.

Bidard, F.C., Pierga, J.Y., Vincent-Salomon, A., and Poupon, M.F. (2008). A 'class action' against the microenvironment: do cancer cells cooperate in metastasis? Cancer Metastasis Rev. 27, 5-10.

Bjorklund, M. and Koivunen, E. (2005). Gelatinase-mediated migration and invasion of cancer cells. Biochim. Biophys. Acta 1755, 37-69.

Braga, V. (2000). The crossroads between cell-cell adhesion and motility. Nat. Cell Biol. 2, E182-E184.

Brew, K. and Nagase, H. (2010). The tissue inhibitors of metalloproteinases (TIMPs): an ancient family with structural and functional diversity. Biochim. Biophys. Acta 1803, 55-71.

Chao, J.C. and Chu, C.C. (2004). Effects of Ginkgo biloba extract on cell proliferation and cytotoxicity in human hepatocellular carcinoma cells. World J. Gastroenterol. 10, 37-41.

Dani, R., Godoy, P., Jardim, M.V., and Raso, P. (1963). In vitro and in vivo study of a trypsin inhibitor in acute pancreatitis: experimental study and a report of its use in human case. Hospital (Rio J.) 64, 635-649.

de Oliveira, C., Santana, L.A., Carmona, A.K., Cezari, M.H., Sampaio, M.U., Sampaio, C.A., and Oliva, M.L. (2001). Structure of cruzipain/cruzain inhibitors isolated from Bauhinia bauhinioides seeds. Biol. Chem. 382, 847-852.

DeClerck, Y.A., Mercurio, A.M., Stack, M.S., Chapman, H.A., Zutter, M.M., Muschel, R.J., Raz, A., Matrisian, L.M., Sloane, B.F., Noel, A., et al. (2004). Proteases, extracellular matrix, and cancer: a workshop of the path B study section. Am. J. Pathol. 164, 1131-1139.

Diasio, R.B. and Johnson, M.R. (2000). The role of pharmacogenetics and pharmacogenomics in cancer chemotherapy with 5fluorouracil. Pharmacology 61, 199-203.

Duffy, M.J. and Duggan, C. (2004). The urokinase plasminogen activator system: a rich source of tumour markers for the individualised management of patients with cancer. Clin. Biochem. 37, 541-548.

Duffy, M.J., McGowan, P.M., and Gallagher, W.M. (2008). Cancer invasion and metastasis: changing views. J. Pathol. 214, 283293.

Egeblad, M. and Werb, Z. (2002). New functions for the matrix metalloproteinases in cancer progression. Nat. Rev. Cancer 2, 161-174.

Fashena, S.J. and Thomas, S.M. (2000). Signalling by adhesion receptors. Nat. Cell Biol. 2, E225-E229.

Fingleton, B. (2007). Matrix metalloproteinases as valid clinical targets. Curr. Pharm. Des. 13, 333-346.

Foekens, J.A., Ries, C., Look, M.P., Gippner-Steppert, C., Klijn, J.G., and Jochum, M. (2003a). Elevated expression of polymorphonuclear leukocyte elastase in breast cancer tissue is associated with tamoxifen failure in patients with advanced disease. Br. J. Cancer 88, 1084-1090.

Foekens, J.A., Ries, C., Look, M.P., Gippner-Steppert, C., Klijn, J.G., and Jochum, M. (2003b). The prognostic value of polymorphonuclear leukocyte elastase in patients with primary breast cancer. Cancer Res. 63, 337-341. 
Fritz, H. and Wunderer, G. (1983). Biochemistry and applications of aprotinin, the kallikrein inhibitor from bovine organs. Arzneimittelforschung 33, 479-494.

Germanov, E., Berman, J.N., and Guernsey, D.L. (2006). Current and future approaches for the therapeutic targeting of metastasis. Int. J. Mol. Med. 18, 1025-1036.

Gocheva, V. and Joyce, J.A. (2007). Cysteine cathepsins and the cutting edge of cancer invasion. Cell Cycle 6, 60-64.

Golubkov, V.S., Cieplak, P., Chekanov, A.V., Ratnikov, B.I., Aleshin, A.E., Golubkova, N.V., Postnova, T.I., Radichev, I.A., Rozanov, D.V., Zhu, W., et al. (2010). Internal cleavages of the autoinhibitory prodomain are required for membrane type 1 matrix metalloproteinase activation, although furin cleavage alone generates inactive proteinase. J. Biol. Chem. 285, 27726-27736.

Han, Y.P., Nien, Y.D., and Garner, W.L. (2002). Tumor necrosis factor- $\alpha$-induced proteolytic activation of pro-matrix metalloproteinase- 9 by human skin is controlled by down-regulating tissue inhibitor of metalloproteinase-1 and mediated by tissue-associated chymotrypsin-like proteinase. J. Biol. Chem. 277, 2731927327.

Hildenbrand, R., Gandhari, M., Stroebel, P., Marx, A., Allgayer, H., and Arens, N. (2008). The urokinase-system - role of cell proliferation and apoptosis. Histol. Histopathol. 23, 227-236.

Hoekstra, R., Eskens, F.A., and Verweij, J. (2001). Matrix metalloproteinase inhibitors: current developments and future perspectives. Oncologist 6, 415-427.

Hoelters, J., Ciccarella, M., Drechsel, M., Geissler, C., Gulkan, H., Bocker, W., Schieker, M., Jochum, M., and Neth, P. (2005). Nonviral genetic modification mediates effective transgene expression and functional RNA interference in human mesenchymal stem cells. J. Gene Med. 7, 718-728.

Itoh, Y. and Seiki, M. (2006). MT1-MMP: a potent modifier of pericellular microenvironment. J. Cell. Physiol. 206, 1-8.

Janicke, F., Prechtl, A., Thomssen, C., Harbeck, N., Meisner, C., Untch, M., Sweep, C.G., Selbmann, H.K., Graeff, H., and Schmitt, M. (2001). Randomized adjuvant chemotherapy trial in high-risk, lymph node-negative breast cancer patients identified by urokinase-type plasminogen activator and plasminogen activator inhibitor type 1. J. Natl. Cancer Inst. 93, 913-920.

Jedeszko, C. and Sloane, B.F. (2004). Cysteine cathepsins in human cancer. Biol. Chem. 385, 1017-1027.

Kallakury, B.V., Karikehalli, S., Haholu, A., Sheehan, C.E., Azumi, N., and Ross, J.S. (2001). Increased expression of matrix metalloproteinases 2 and 9 and tissue inhibitors of metalloproteinases 1 and 2 correlate with poor prognostic variables in renal cell carcinoma. Clin. Cancer Res. 7, 3113-3119.

Kessenbrock, K., Plaks, V., and Werb, Z. (2010). Matrix metalloproteinases: regulators of the tumor microenvironment. Cell 141, 52-67.

Koblinski, J.E., Ahram, M., and Sloane, B.F. (2000). Unraveling the role of proteases in cancer. Clin. Chim. Acta 291, 113-135.

Lah, T.T., Duran Alonso, M.B., and Van Noorden, C.J. (2006). Antiprotease therapy in cancer: hot or not? Expert Opin. Biol. Ther. 6, 257-279.

Lazar, M., Sullivan, J., Chipitsyna, G., Gong, Q., Ng, C.Y., Salem, A.F., Aziz, T., Witkiewicz, A., Denhardt, D.T., Yeo, C.J., et al. (2010). Involvement of osteopontin in the matrix-degrading and proangiogenic changes mediated by nicotine in pancreatic cancer cells. J. Gastrointest. Surg. 14, 1566-1577.

Leipner, J. and Saller, R. (2000). Systemic enzyme therapy in oncology: effect and mode of action. Drugs 59, 769-780.

Liotta, L.A. and Clair, T. (2000). Cancer. Checkpoint for invasion. Nature 405, 287-288.
Liu, D., Nakano, J., Ishikawa, S., Yokomise, H., Ueno, M., Kadota, K., Urushihara, M., and Huang, C.L. (2007). Overexpression of matrix metalloproteinase-7 (MMP-7) correlates with tumor proliferation, and a poor prognosis in non-small cell lung cancer. Lung Cancer 58, 384-391.

Lopez-Otin, C. and Matrisian, L.M. (2007). Emerging roles of proteases in tumour suppression. Nat. Rev. Cancer 7, 800-808.

Lukashev, M.E. and Werb, Z. (1998). ECM signalling: orchestrating cell behaviour and misbehaviour. Trends Cell Biol. 8, 437-441.

Macedo, M.L., Durigan, R.A., da Silva, D.S., Marangoni, S., Freire, M.G., and Parra, J.R. (2010). Adenanthera pavonina trypsin inhibitor retard growth of Anagasta kuehniella (Lepidoptera: Pyralidae). Arch. Insect Biochem. Physiol. 73, 213-231.

Martin, M.D. and Matrisian, L.M. (2007). The other side of MMPs: protective roles in tumor progression. Cancer Metastasis Rev. 26, $717-724$.

Miyasaka, M. (1995). Cancer metastasis and adhesion molecules. Clin. Orthop. Relat. Res. 312, 10-18.

Moll, U.M., Youngleib, G.L., Rosinski, K.B., and Quigley, J.P. (1990). Tumor promoter-stimulated Mr 92,000 gelatinase secreted by normal and malignant human cells: isolation and characterization of the enzyme from HT1080 tumor cells. Cancer Res. 50, 6162-6170.

Morrison, J.F. (1982). The slow-binding and slow, tight-binding inhibition of enzyme-catalysed reactions. Trends Biochem. Sci. 7, 102-105.

Murphy, G. and Crabbe, T. (1995). Gelatinases A and B. Methods Enzymol. 248, 470-484.

Nagase, H. and Woessner, J.F. Jr. (1999). Matrix metalloproteinases. J. Biol. Chem. 274, 21491-21494.

Nagase, H., Visse, R., and Murphy, G. (2006). Structure and function of matrix metalloproteinases and TIMPs. Cardiovasc. Res. 69, 562-573.

Nakahata, A.M., Bueno, N.R., Rocha, H.A., Franco, C.R., Chammas, R., Nakaie, C.R., Jasiulionis, M.G., Nader, H.B., Santana, L.A., Sampaio, M.U., et al. (2006). Structural and inhibitory properties of a plant proteinase inhibitor containing the RGD motif. Int. J. Biol. Macromol. 40, 22-29.

Nguyen, T.H. (2004). Mechanisms of metastasis. Clin. Dermatol. 22, 209-216.

Noel, A., Jost, M., and Maquoi, E. (2008). Matrix metalloproteinases at cancer tumor-host interface. Semin. Cell Dev. Biol. 19, 52-60.

Nozawa, F., Hirota, M., Okabe, A., Shibata, M., Iwamura, T., Haga, Y., and Ogawa, M. (2000). Elastase activity enhances the adhesion of neutrophil and cancer cells to vascular endothelial cells. J. Surg. Res. 94, 153-158.

Ohkoshi, M. and Sasaki, Y. (2005). Antimetastatic activity of a synthetic serine protease inhibitor, FOY-305 (Foypan). In Vivo 19, 133-136.

Oliva, M.L. and Sampaio, U.M. (2008). Bauhinia Kunitz-type proteinase inhibitors: structural characteristics and biological properties. Biol. Chem. 389, 1007-1013.

Oliva, M.L. and Sampaio, M.U. (2009). Action of plant proteinase inhibitors on enzymes of physiopathological importance. An. Acad. Bras. Cienc. 81, 615-621.

Oliva, M.L., Mendes, C.R., Santomauro-Vaz, E.M., Juliano, M.A., Mentele, R., Auerswald, E.A., Sampaio, M.U., and Sampaio, C.A. (2001). Bauhinia bauhinioides plasma kallikrein inhibitor: interaction with synthetic peptides and fluorogenic peptide substrates related to the reactive site sequence. Curr. Med. Chem. 8, 977-984.

Parise, L.V., Lee, J., and Juliano, R.L. (2000). New aspects of integrin signaling in cancer. Semin. Cancer Biol. 10, 407-414. 
Park, C.C., Bissell, M.J., and Barcellos-Hoff, M.H. (2000). The influence of the microenvironment on the malignant phenotype. Mol. Med. Today 6, 324-329.

Prasad, E.R., Dutta-Gupta, A., and Padmasree, K. (2010). Purification and characterization of a Bowman-Birk proteinase inhibitor from the seeds of black gram (Vigna mungo). Phytochemistry $71,363-372$.

Ramos-DeSimone, N., Hahn-Dantona, E., Sipley, J., Nagase, H., French, D.L., and Quigley, J.P. (1999). Activation of matrix metalloproteinase-9 (MMP-9) via a converging plasmin/stromelysin-1 cascade enhances tumor cell invasion. J. Biol. Chem. 274, 13066-13076.

Roghi, C., Jones, L., Gratian, M., English, W.R., and Murphy, G. (2010). Golgi reassembly stacking protein 55 interacts with membrane-type (MT) 1-matrix metalloprotease (MMP) and furin and plays a role in the activation of the MT1-MMP zymogen. FEBS J. 277, 3158-3175.

Roy, S. and Dutta, S.K. (2009). Genomic and cDNA cloning, expression, purification, and characterization of chymotrypsintrypsin inhibitor from winged bean seeds. Biosci. Biotechnol. Biochem. 73, 2671-2676.

Sato, T., Takahashi, S., Mizumoto, T., Harao, M., Akizuki, M., Takasugi, M., Fukutomi, T., and Yamashita, J. (2006). Neutrophil elastase and cancer. Surg. Oncol. 15, 217-222.

Seiki, M. (2003). Membrane-type 1 matrix metalloproteinase: a key enzyme for tumor invasion. Cancer Lett. 194, 1-11.

Shamamian, P., Schwartz, J.D., Pocock, B.J., Monea, S., Whiting, D., Marcus, S.G., and Mignatti, P. (2001). Activation of progelatinase A (MMP-2) by neutrophil elastase, cathepsin G, and proteinase-3: a role for inflammatory cells in tumor invasion and angiogenesis. J. Cell. Physiol. 189, 197-206.

Skrzydlewska, E., Sulkowska, M., Koda, M., and Sulkowski, S. (2005). Proteolytic-antiproteolytic balance and its regulation in carcinogenesis. World J. Gastroenterol. 11, 1251-1266.

Sloane, B.F., Sameni, M., Podgorski, I., Cavallo-Medved, D., and Moin, K. (2006). Functional imaging of tumor proteolysis. Annu. Rev. Pharmacol. Toxicol. 46, 301-315.

Sorsa, T., Salo, T., Koivunen, E., Tyynela, J., Konttinen, Y.T., Bergmann, U., Tuuttila, A., Niemi, E., Teronen, O., Heikkila, P., et al. (1997). Activation of type IV procollagenases by human tumor-associated trypsin-2. J. Biol. Chem. 272, 21067-21074.

Stanton, H., Gavrilovic, J., Atkinson, S.J., d'Ortho, M.P., Yamada,
K.M., Zardi, L., and Murphy, G. (1998). The activation of ProMMP-2 (gelatinase A) by HT1080 fibrosarcoma cells is promoted by culture on a fibronectin substrate and is concomitant with an increase in processing of MT1-MMP (MMP-14) to a 45 kDa form. J. Cell Sci. 111, 2789-2798.

Stearns, M. and Stearns, M.E. (1996). Evidence for increased activated metalloproteinase 2 (MMP-2a) expression associated with human prostate cancer progression. Oncol. Res. 8, 69-75.

Sternlicht, M.D. and Werb, Z. (2001). How matrix metalloproteinases regulate cell behavior. Annu. Rev. Cell Dev. Biol. 17, $463-516$.

Sumikawa, J.T., Nakahata, A.M., Fritz, H., Mentele, R., Sampaio, M.U., and Oliva, M.L. (2006). A Kunitz-type glycosylated elastase inhibitor with one disulfide bridge. Planta Med. 72, 393397.

Sun, Z. and Yang, P. (2004). Role of imbalance between neutrophil elastase and $\alpha 1$-antitrypsin in cancer development and progression. Lancet Oncol. 5, 182-190.

Turk, B. (2006). Targeting proteases: successes, failures and future prospects. Nat. Rev. Drug Discov. 5, 785-799.

Turpeenniemi-Hujanen, T. (2005). Gelatinases (MMP-2 and -9) and their natural inhibitors as prognostic indicators in solid cancers. Biochimie 87, 287-297.

Werb, Z. (1997). ECM and cell surface proteolysis: regulating cellular ecology. Cell 91, 439-442.

Will, H., Atkinson, S.J., Butler, G.S., Smith, B., and Murphy, G. (1996). The soluble catalytic domain of membrane type 1 matrix metalloproteinase cleaves the propeptide of progelatinase A and initiates autoproteolytic activation. Regulation by TIMP-2 and TIMP-3. J. Biol. Chem. 271, 17119-17123.

Wolf, K. and Friedl, P. (2006). Molecular mechanisms of cancer cell invasion and plasticity. Br. J. Dermatol. 154 (Suppl. 1), 11-15.

Woodhouse, E.C., Chuaqui, R.F., and Liotta, L.A. (1997). General mechanisms of metastasis. Cancer 80 (Suppl. 8), 1529-1537.

Zucker, S., Pei, D., Cao, J., and Lopez-Otin, C. (2003). Membrane type-matrix metalloproteinases (MT-MMP). Curr. Top. Dev. Biol. 54, 1-74.

Received July 27, 2010; accepted October 27, 2010 